\title{
Expression of Spermatogonial and Pluripotency Markers in Spermatogonial Stem Cells after Treatment with Different Culture Factors
}

\author{
Hatef Ghasemi Hamidabadi ${ }^{1}$, Nourollah Rezaei ${ }^{1}$, Reza Mahmoudi ${ }^{2}$, Maryam Nazm Bojnordi ${ }^{1 *}$ \\ ${ }^{1}$ Department of Anatomy \& Cell Biology, Molecular and Cell Biology Research Center, Hemoglobinopathy Institute, Faculty of Medicine, \\ Mazandaran University of Medical Sciences, Sari, Iran. \\ ${ }^{2}$ Cellular \& Molecular research center, Yasuj University of Medical Sciences, Yasuj, Iran.
}

Received: 17 Mar 2014

Revised : 29 Apr 2014

Accepted: 16 May 2014

Corresponding Authors:

Maryam Nazm Bojnordi \& Reza

Mahmoudi

Department of Anatomy \& Cell

Biology, Faculty of Medicine,

Mazandaran University of Medical

Sciences, Sari, Iran.

Phone: +98-9122176621

P.O.Box: 48471-91971

E-mail: bojnordi@modares.ac.ir

\begin{abstract}
Background: As condition and component of culture determine fate map of spermatogonial stem cells (SSCs), the aim of this study was to evaluate of growth factors GDNF, LIF and RA on proliferation and differentiation of SSC.

Materials and Methods: SSCs were cultured in two groups: The first group GDNF and LIF and the second group RA. The number of clumps and colony formation was monitored during 1 month in culture. To identification of the colony, stained with PLZF using immunostaining. Pluripotency gene Oct 4 and neural markers MAP2, NeuroD and Nestin were analyzed by RT-PCR.

Results: In the presence of GDNF and LIF, cells proliferated rapidly and many compact clumps were appeared whereas after exposure to RA cells formed small clumps. The results of immunocytochemistry shows PLZF was detected in the group GDNF \& LIF. RT-PCR showed high level expression Oct 4 in the group GDNF and LIF whereas neural markers MAP2, NeuroD and Nestin were expressed in the group RA.

Conclusions: GDNF and LIF are essential for self-renewal and colony formation of SSCs that confirm the stem cells activity of these cells but RA inhibits stem cell activity of SSCs and induces neural differentiation of these.
\end{abstract}

Keywords: Spermatogonial stem cells; Leukemia Inhibitory Factor; Glial cell line-derived neurotropic factor; Retinoic acid

Please cite this article as: Ghasemi Hamidabadi H, Rezaei N, Mahmoudi R, Nazm Bojnordi M. Expression of Spermatogonial and Pluripotency Markers in Spermatogonial Stem Cells after Treatment with Different Culture Factors. Res Mol Med. 2014; 2 (2): 16-21

\section{Introduction}

Spermatogonia stem cells (SSCs) are a unique population of gremline stem cells in testis that has proliferation and self-renewal activity as well as genetic transfer using spermatogenesis (1). Recently, in vitro differentiation of SSCs has attracted wide interest as an experimental model for understanding developmental pathways and mechanisms. Also, the isolation of SSCs has raised the possibility that in vitro differentiation may provide a novel source of cells for medical treatment.

Early work on mouse SSCs in vitro differentiation was performed by some researchers. These experiments proved that the SSCs are responds to culture conditions (2-4). It seems that undefined component of culture determined the fate map of SSCs whether they are cells that has proliferation and self-renewal activity or they are the cells with differentiation activity (1-2). The survival growth and differentiation of SSCs depends on the culture conditions; for example several growth factors are essential for SSCs proliferation and colony formation (2-5). Identification of specific growth factors for expansion of SSCs in vitro has been investigated in many laboratories (4-5). Some investigators reported that glial cell line-derived neurotropic factor (GDNF) is an essential component for propagation of SSCs by preventing them of apoptosis as well as its combination with other growth factors elicits effect. These growth factors with variable range of biological actions in different tissues mediate activation of intracellular pathway (6-9) and an act synergistically to support in vitro expansion of SSCs 
(10). In contrast, new research showed that transdifferentiation of SSCs into various cell types including ectodermal layer (neuroprogenitor, neuron and glial cells), mesodermal layer (cardiomyocyte and skeletal muscles) and endodermal layer (hepatocyts) (11-15). Since the effect of culture conditions component in proliferation or differentiation of SSCs, the objection of this study was to evaluation the effect of growth factors GDNF and Leukemia Inhibitory Factor (LIF) as well as inducer retinoic acid (RA) or proliferation or differentiation of SSCs. The growth factors of GDNF and LIF were added and hypothesis that stem cell activity and colony formation of SSCs could be sustain in this system in comparison with the addition of RA.

\section{Materials and Methods}

Collection and in vitro culture of spermatogonia cells Neonatal NMRI mice (2-4 days old, $n=5$ per each group) were used. Testis cells suspension were collected from each mouse following enzymatic digestions and purification steps. After decapsulation of the testis, tissue was mechanically dissected and dissociated via a two-step mechanical and enzymatic digestion with DMEM medium which contained; 0.5 $\mathrm{mg} / \mathrm{ml}$ collagenase-dispase, $0.5 \mathrm{mg} / \mathrm{ml}$ trypsin and $0.05 \mathrm{mg} / \mathrm{ml}$ DNase, (with shaking and pipeting) at 37 ${ }^{\circ} \mathrm{C}$ for 30-45 minute (min). Enzymes were purchased from Sigma Company (Sigma, St. Louis, MO, USA). Clumps of cells remained of this treatment (a mixture of spermatogonia and sertoli cells) were centrifuged and washed twice and fresh medium was added. The Sertoli cells were isolated from spermatogonia cells according a procedure described by Scarpino (16). Briefly, Petri dishes were coated with a solution of 5 $\mu \mathrm{g} / \mathrm{ml}$ of datura stramonium agglutinin (DSA; Sigma, USA) in phosphate-buffered saline (PBS) for $30 \mathrm{~min}$. The mixture population of the cells was incubated in lectin-coated dishes for 1 hour (hr). Then non adherent cells (spermatogonia cells) were collected and cultured in Dulbecco's modified Eagle's medium (DMEM) (Invitrogen) supplemented with 15\% FBS, $1 \mathrm{mM}$ L glutamine (Invitrogen), $0.1 \mathrm{mM}$ nonessential amino acids (Invitrogen), $0.1 \mathrm{mM}$-mercaptoethanol at $37{ }^{\circ} \mathrm{C}$ and $5 \% \mathrm{CO} 2$, in a humidified atmosphere. The cells were divided in three groups. The first group which received GDNF and LIF (experimental 1), the second group which received RA (experimental 2) and control group which received no growth factors. The cells were cultured for one month and monitored every day and their medium was changed twice a week.

\section{Morphological evaluation of colonies}

Evaluation of SSCs derived colonies was started after 4 days of culture and carried on every seven days during one month culture by inverted microscopic and the numbers of colonies were determined in each groups. Results from three separate experiments were used to calculated means \pm SD. During this period, the cellular morphology and the ability of colony formation were evaluated and compared between mentioned groups.

\section{Alkaline phosphates (ALP) activity}

ALP reaction as a marker of SSCs was evaluated in our study. For detection of ALP activity in colonies, the Spermatoginial derived cell colonies were washed three times in PBS and were fixed in a solution containing $2.5 \mathrm{ml}$ citrate, $6.5 \mathrm{ml}$ acetone and $0.6 \mathrm{ml}$ formaldehyde in distilled water for $30 \mathrm{~min}$ at room temperature (RT) and incubated in a solution containing $0.5 \mathrm{mg} / \mathrm{ml}$ Fast Red Violet (Sigma) and 40 $\mu \mathrm{l} / \mathrm{ml} \alpha$-naphthol phosphate $(0.25 \%$ solution $)$ for 30 min. The ALP activity of these colonies was observed using light microscopy (17).

Table 1. Quantitative RT-PCR Primer Sequences.

\begin{tabular}{lll}
\hline Gene & Primer(forward/reverse) & Significance \\
\hline \multirow{2}{*}{ GAPDH } & 5'- ACCACAGTCCATGCCATAC-3' & Internal Control \\
& 5' - TCCACCACCCTGTTCTGTA-3' & \\
Oct-4 & 5'- GTTCTCTTTGGAAAGGTGTTC-3' & Pluripotency marker \\
& 5'- GCATATCTCCTGAAGGTCTC-3' & \\
MAP2 & 5'- AATAGACCTAAGCCATGTGACATCC-3' & Neuroprogenitor marker \\
& 5'- AGAACCAACTTTAGCTTGGCC-3' & \\
NeuroD & 5'- AAGCACCAGATGGCACTGTC-3' & Neuroprogenitor marker \\
& 5'- CAGGACTTGCATTCGATACAC-3' & \\
Nestin & 5'- AGTGTGAAGGCAAAGATAGC-3' & Neuroprogenitor marker \\
\end{tabular}




\section{Immunocytochemical evaluation}

The colony cells in each group were washed with PBS and fixed in $4 \%$ parformaldehyde (PFA) for 30 min at RT. Fixed cells were permeabilized with $0.2 \%$ Triton X-100 for $10 \mathrm{~min}$ at RT followed by three washes with PBS. To block unspecific binding of the antibody, the cells were incubated with $10 \%$ goat serum for $30 \mathrm{~min}$ at RT. The cells were incubated with primary antibody promyelocytic leukemia zincfinger (PLZF, Rabbit polyclonal IgG, ab39354, abcam system) which diluted $1: 200$ in $\mathrm{PBS} / 1 \%$ bovine serum albumin (BSA) for overnight $(\mathrm{O} / \mathrm{N})$ at $4^{\circ} \mathrm{C}$. Further incubation with the secondary antibody Phycoerythrin (PE) -conjugated Donkey polyclonal secondary antibody to Rabbit IgG (ab7007, abcam system) was performed for $45 \mathrm{~min}$ at RT in dark and the cells were washed three times in PBS. Nuclei were detected by DAPI (sigma) staining. Images were captured with an Olympus phase contrast microscope (BX51, Olympus, Tokyo, Japan) (18-19).

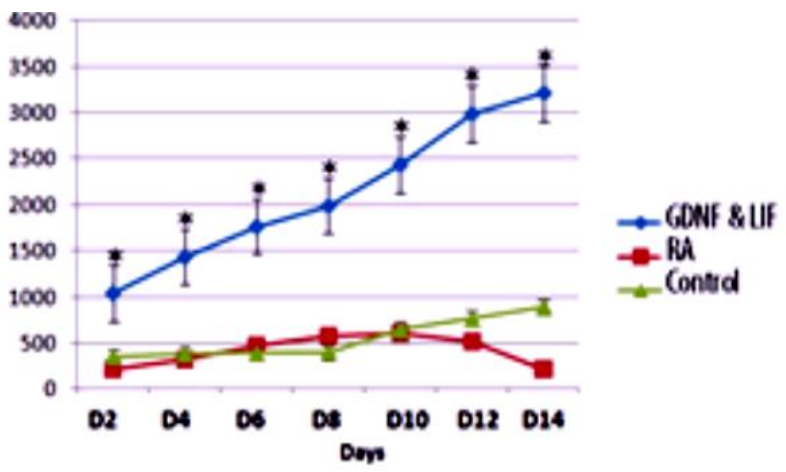

Figure 1. The number of clumps in D2 to D14 in GDNF \& LIF group, RA group and control group. Asterisks represent significance.

\section{RNA isolation and RT-PCR Analysis}

The colony cells were collected at the designated periods of the culture by aspiration into an eppendorf tube, centrifuged, and the supernatant discarded. Total RNA was extracted using the qiazol lyses reagent (Qiagen) according to the manufacturer's instructions. Total RNA was quantified and $5 \mu \mathrm{g}$ was used for cDNA synthesis using random primers (Fermentas) under standard conditions. RT-PCR amplifications were conducted for 3 minutes at $95{ }^{\circ} \mathrm{C}\left(95^{\circ} \mathrm{C}, 30\right.$ seconds; $60{ }^{\circ} \mathrm{C}, 45$ seconds; and $72{ }^{\circ} \mathrm{C}, 45$ seconds) for 40 cycles and $72{ }^{\circ} \mathrm{C}$ for $7 \mathrm{~min}$ for the final extension. Primer sequences are shown in table 1 (20-22).

\section{Statistical analysis}

Quantitative data was expressed as mean plus or minus SEM from at least three experiments. ANOVA was used for statistical analysis with $\mathrm{P}$ values less than 0.05 which was significant.

\section{Results}

In vitro proliferation and colonization ability of SSCs cultured in different condition mediums

Our results showed in the presence of GDNF and LIF, SSCs proliferated greater than those cultured exposure with RA. Addition of growth factors GDNF and LIF to the culture medium increased significant expansion of the germ cell clumps in compare to RA (Figure 1). These slightly attached clump-like structures ( $\geq 10$ cells) on the bottom of dishes were appeared 2 days after seeding. The clumps were dissociated by trypsinization and then re-plated every 2 weeks using the same medium. In addition after each subculture cells divided and regenerated clumps again, whereas after exposure to RA cells formed small clumps, that gradually disappeared after subsequent subculture (Figure 1).

In the presence of GDNF and LIF, approximately $1 \times$ 106 colonies (mean \pm SEM, $n=5$ ) formed after one month of culture but no colony was observed in cultures exposure to RA (Figure 2). Also the colony formation that is a criterion proves stem cell activity was gradually disappeared without GDNF and LIF (Figure 2).

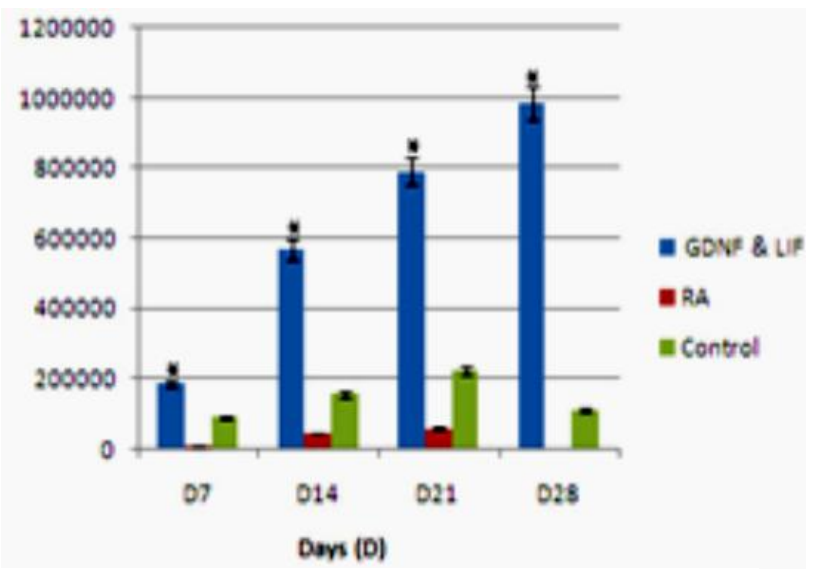

Figure 2. The number of colonies in D2 to D14 in GDNF \& LIF group, RA group and Control Asterisks represent significance.

These evidences show that the growth factors GDNF and LIF are essential for proliferation and colonization of SSCs.

\section{ALP reactivity}

The colonies appeared in group treated GDNF \& LIF show ALP reactivity (Figure 3 ).

\section{Immunocytochemistry staining}

The results of immunocytochemistry staining shows that PLZF, which is a nuclear marker for SSCs, was detected in the group received GDNF \& LIF (Figure $4 \mathrm{C}$ and $4 \mathrm{~F})$. 
Expression of subset of spermatogonia gene (Oct4) and neural genes (NeuroD, MAP2 and Nestin) in SSCs cultured in different condition medium

The results of RT-PCR evaluation showed high level expression of pluripotency gene Oct 4 in the group which received GDNF and LIF, whereas this gene has no expression in the cells exposured to RA. Furthermore to confirm neural characteristic of differentiated cells after treatment with RA, we investigated and detected sharp bands of some neural markers microtubule-associated protein 2 (MAP2), NeuroD and Nestin in these cells, whereas approximately no neural gene expression were detected in the group treated with GDNF and LIF (Figure 5).

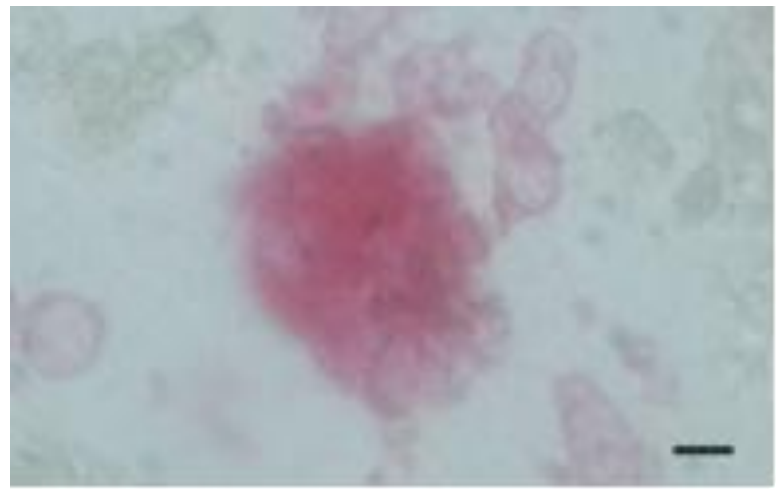

Figure 3. SSCs colonies are positive to ALP staining which treated with GDNF and LIF.

\section{Discussion}

The culture conditions and components can affect the maintenance of stem cell pluripotency or limit potential of SSCs to pluripotency. This makes valuable model which clear the molecular and cellular events that occur in male germ stem cells development and it is useful in therapeutic strategies for treatment of male infertility $(7,17,23)$. Furthermore, recent researches show another new differentiation activity of SSCs into all three germ layers including ectodermal, mesodermal and endodermal layers $(13,15,24-25)$. Generation of pluripotent stem cells which has differentiated activity from both neonatal and adult SSCs is proved by Shinohara and Guan (25-26). The condition culture described in our research evaluated the individual growth factors (GDNF and LIF) for SSCs proliferation and furthermore, we compare it with differentiation culture conditions using RA. The effect of different growth factors on SSCs proliferation was reported by some investigators for example Kubota demonstrated that GDNF increased SSCs proliferation $(23,27-28)$. These results are the same as Nagano reported similar finding in SSCs culture exposure to GDNF (10). Similar results have obtained from in vitro culture of SSCs from other species so, in our research we culture SSCs with growth factors GDNF and LIF. LIF used in our research has a notable value in germ cell development and function $(4,19,29)$. The other factor which used to enhance proliferation activity of SSCs was GDNF, proposed to be an important growth factor for communication between spermatogonia and sertoli cells that promotes the proliferation of undifferentiated spermatogonia both in vitro and in vivo $(7,30-31)$.
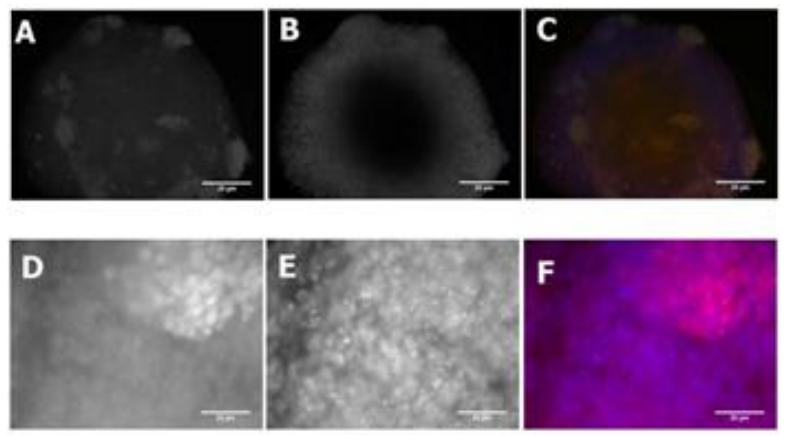

Figure 4. Expression of PLZF protein in group that received GDNF and LIF was analyzed by Immunocytochemistry. (A) PLZF (red), (B) Nuclei were stained by DAPI (blue) and (C) merged, magnification is $\times 10$. (D) PLZF (red), (E) Nuclei DAPI (blue) and (F) merged, magnification is $\times 40$. Scale bars: $20 \mu \mathrm{m}$.

Several recent studies have demonstrated that GDNF is an important factor for promoting spermatogonial self-renewal and that its receptor GFRA1 is expressed on undifferentiated spermatogonia, possibly including SSCs .(17-19, 30).

The combination of GDNF and LIF very used to optimize a culture condition media to support proliferation and self-renewal in SSCs for generation of high percentage of colonies (9). Our resulted showed that this mentioned growth factors provide a useable environment for proliferation and colony formation of SSCs. In our experiment some criteria such as; morphology and alkaline phosphates activity were utilized as parameter for colony characterization, in addition germ cells specific marker detection was carried out using PLZF immunocytochemistry techniques. Also the stem cell activity characteristic of SSCs colonies was confirmed by the expression of Oct4 gene in molecular level.

In contrast no colony was appeared in the group received RA and cells showed some morphological changes seems they differentiated into neural cells with long numerous process. The neural differentiation was confirmed by morphological changes and expression of some specific neural genes such as NeuroD, MAP2 and Nestin. In addition the expression of pluripotency gene (Oct4) in the 
differentiated cells was not expressed which confirms the reduction of undifferentiated characteristic of this cells. In fact Oct4 has been shown to function as core transcription factor in maintain self-renewal of embryonic stem cells and SSCs.

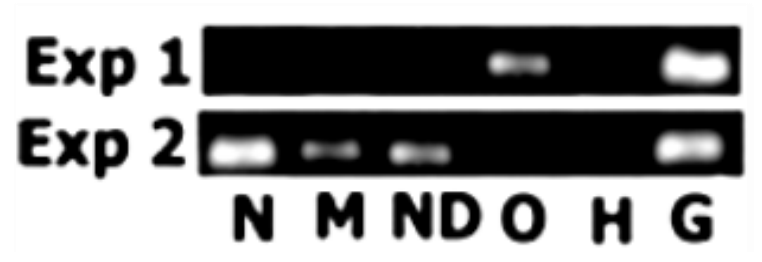

Figure 5. Reverse transcription-polymerase chain reaction (RTPCR) for markers of Oct4 (O), MAP2 (M), NeuroD (ND) and Nestin (N). (A) RNA was prepared from the group that received GDNF and LIF (Exp1). (B) RNA was prepared from group that received RA (Exp2). GAPDH served as an internal mRNA control.

This data is similar to previous results that reported the differentiation of SSCs into different lineage specifically neural precursor under the define culture conditions (13, 15, 32-33). Mizrak et al mentioned that culture conditions support the differentiation of SSCs (14). In a study by Glaser, the positive effect of RA was reported in neural differentiation of SSCs $(26,33)$.

Conclusion: Based on the result obtained in our research, using GDNF and LIF was effective in proliferation and colony formation, in other word in comparison with control group the addition of GDNF and LIF leads to a large compact colonies whereas in cells treated with RA there was small colonies disappeared gradually during subculture. This finding is an agreement with that reported by how demonstrated effects of growth factors on colony formation of SSCs.

\section{Acknowledgment}

We thank the Anatomy \& Cell Biology Department of Mazandaran University of Medical Sciences and Latifpour M, Ph.D student of Tehran University of Medical Sciences, for their assistance. This study did not have any conflict of interest.

\section{References}

1. Izadyar F, Den Ouden K, Stout T, Stout J, Coret J, Lankveld D, et al. Autologous and homologous transplantation of bovine spermatogonial stem cells. Reproduction. 2003; 126 (6): 765-74. PMID: 14748695

2. de Rooij DG. Rapid expansion of the spermatogonial stem cell tool box. Proc Natl Acad Sci U S A. 2006; 103 (21): 7939-40. PMID: 16705034

3. Ehmcke J, Schlatt S. A revised model for spermatogonial expansion in man: lessons from non-human primates. Reproduction. 2006; 132 (5): 673-80. PMID: 17071768

4. Kuijk EW, Colenbrander B, Roelen BA. The effects of growth factors on in vitro-cultured porcine testicular cells. Reproduction. 2009; 138 (4): 721-31. PMID: 19633132

5. Huleihel M, AbuElhija M, Lunenfeld E. In vitro culture of testicular germ cells: regulatory factors and limitations. Growth Factors. 2007; 25 (4): 236-52. PMID: 180922032

6. Abé K, Eto K, Abé S-i. Epidermal growth factor mediates spermatogonial proliferation in newt testis. Reprod Biol Endocrinol. 2008; 6 (7): 1-13. PMID: 18254942

7. Aponte PM, Soda T, Van de Kant H, de Rooij DG. Basic features of bovine spermatogonial culture and effects of glial cell line-derived neurotrophic factor. Theriogenology. 2006; 65 (9): 1828-47. PMID: 16321433

8. Buageaw A, Sukhwani M, Ben-Yehudah A, Ehmcke J, Rawe VY, Pholpramool C, et al. GDNF family receptor alpha1 phenotype of spermatogonial stem cells in immature mouse testes. Biol Reprod. 2005; 73 (5): 1011-6. PMID: 16014811

9. Kubota H, Avarbock MR, Brinster RL. Culture conditions and single growth factors affect fate determination of mouse spermatogonial stem cells. Biol Reprod. 2004; 71 (3): 722-31. PMID: 15115718

10. Mohamadi S, Movahedin M, Koruji S, Jafarabadi MA, Makoolati Z. Comparison of colony formation in adult mouse spermatogonial stem cells developed in Sertoli and STO coculture systems. Andrologia. 2012; 44 (s1): 431-7. PMID: 21762195

11. de Rooij DG, Mizrak SC. Deriving multipotent stem cells from mouse spermatogonial stem cells: a new tool for developmental and clinical research. Development 2008; 135 (13): 2207-13. PMID: 18495819

12. Kossack N, Meneses J, Shefi S, Nguyen HN, Chavez S, Nicholas C, et al. Isolation and Characterization of Pluripotent Human Spermatogonial Stem Cell-Derived Cells. Stem Cells. 2009; 27 (1): 138-49. PMID: 18927477

13. Mardanpour P, Guan K, Nolte J, Lee JH, Hasenfuss G, Engel $\mathrm{W}$, et al. Potency of germ cells and its relevance for regenerative medicine. J Anat. 2008; 213 (1): 26-9.

14. Mizrak S, Chikhovskaya J, Sadri-Ardekani H, Van Daalen S, Korver C, Hovingh S, et al. Embryonic stem cell-like cells derived from adult human testis. Hum Reprod. 2010; 25 (1): 158-67. PMID: 19815622

15. Nayernia K. Stem cells derived from testis show promise for treating a wide variety of medical conditions. Cell Res. 2007; 17 (11): 895-7. PMID: 18004392

16. Scarpino S, Rita Morena A, Petersen C, Fröysa B, Söder O, Boitani C. A rapid method of Sertoli cell isolation by DSA lectin, allowing mitotic analyses. Mol Cell Endocrinol. 1998; 146 (1): 121-7. PMID: 10022769

17. Mirzapour T, Movahedin M, Tengku Ibrahim T, Koruji M, Haron A, Nowroozi M, et al. Effects of basic fibroblast growth factor and leukaemia inhibitory factor on proliferation and short-term culture of human spermatogonial stem cells. Andrologia. 2012; 44 (s1): 41-55. PMID: 21806653

18. Dann CT, Alvarado AL, Molyneux LA, Denard BS, Garbers DL, Porteus MH. Spermatogonial Stem Cell Self-Renewal Requires OCT4, a Factor Downregulated During Retinoic Acid-Induced Differentiation. Stem Cells. 2008; 26 (11): 2928-37. PMID: 18719224 
19. Hamidabadi HG, Pasbakhsh P, Amidi F, Soleimani M, Forouzandeh M, Sobhani A. Functional Concentrations of BMP4 on Differentiation of Mouse Embryonic Stem Cells to Primordial Germ Cells. Int J Fertil Steril. 2011; 5 (2): 104-9. PMID: 24963367

20. Huang Y-H, Chin C-C, Ho H-N, Chou C-K, Shen C-N, Kuo H$\mathrm{C}$, et al. Pluripotency of mouse spermatogonial stem cells maintained by IGF-1-dependent pathway. FASEB J. 2009; 23 (7): 2076-87. PMID: 19246485

21. Izadyar F, Pau F, Marh J, Slepko N, Wang T, Gonzalez R, et al. Generation of multipotent cell lines from a distinct population of male germ line stem cells. Reproduction. 2008; 135 (6): 771-84. PMID: 18502893

22. Kaka G, Tiraihi T, Arab Kheradmand J, Azizzadeh Delshad A A study on in-vitro transdifferentiation of rat bone marrow stromal cells into neuroepithelial-like cells. Iran Red Crescent Med J. 2009; 11: 133-9.

23. Kubota H, Avarbock MR, Brinster RL. Growth factors essential for self-renewal and expansion of mouse spermatogonial stem cells. Proc Natl Acad Sci U S A. 2004; 101 (47): 16489-94. PMID: 15520394

24. Guan K, Nayernia K, Maier LS, Wagner S, Dressel R, Lee JH, et al. Pluripotency of spermatogonial stem cells from adult mouse testis. Nature. 2006; 440 (7088): 1199-203. PMID: 16565704

25. Guan K, Wagner S, Unsöld B, Maier LS, Kaiser D, Hemmerlein B, et al. Generation of functional cardiomyocytes from adult mouse spermatogonial stem cells. Circ Res. 2007; 100 (11):1615-25. PMID: 17478732

26. Kanatsu-Shinohara M, Inoue K, Lee J, Yoshimoto M, Ogonuki $\mathrm{N}$, Miki $\mathrm{H}$, et al. Generation of pluripotent stem cells from neonatal mouse testis. Cell. 2004; 119 (7): 1001-12. PMID: 15620358
27. Kubota H, Brinster RL. Technology insight: in vitro culture of spermatogonial stem cells and their potential therapeutic uses. Nat Clin Pract Endocrinol Metab. 2006; 2 (2): 99-108. PMID: 16932264

28. Maden M, Sonneveld E, van der Saag PT, Gale E. The distribution of endogenous retinoic acid in the chick embryo: implications for developmental mechanisms. Development. 1998; 125 (21): 4133-44. PMID: 9753668

29. de Sousa Lopes SMC, Roelen BA, Monteiro RM, Emmens R, Lin HY, Li E, et al. BMP signaling mediated by ALK2 in the visceral endoderm is necessary for the generation of primordial germ cells in the mouse embryo. Genes Dev. 2004; 18 (15): 183849. PMID: 15289457

30. Meng X, Lindahl M, Hyvönen ME, Parvinen M, de Rooij DG, Hess MW, et al. Regulation of cell fate decision of undifferentiated spermatogonia by GDNF. Science. 2000; 287 (5457): 1489-93.

31. Yomogida K, Yagura Y, Tadokoro Y, Nishimune Y. Dramatic expansion of germinal stem cells by ectopically expressed human glial cell line-derived neurotrophic factor in mouse Sertoli cells. Biol Reprod. 2003; 69 (4): 1303-7. PMID: 12801989

32. Bojnordi MN, Movahedin M, Tiraihi T, Javan M. Alteration in genes expression patterns during in vitro differentiation of mouse spermatogonial cells into neuroepithelial-like cells. Cytotechnology. 2013; 65 (1): 97-104. PMID: 23104269

33. Glaser T, Opitz T, Kischlat T, Konang R, Sasse P, Fleischmann $\mathrm{BK}$, et al. Adult germ line stem cells as a source of functional neurons and glia. Stem Cells. 2008; 26 (9): 2434-43. PMID: 18635869 